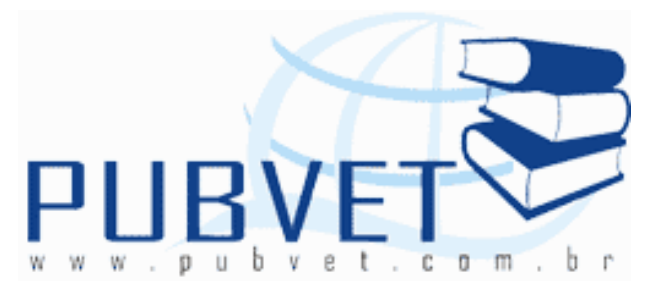

PUBVET, Publicações em Medicina Veterinária e Zootecnia.

\title{
Acidulantes na água de codornas japonesas (Coturnix japonica) alojadas sob diferentes densidades
}

\author{
Sérgio Kenji Kakimoto ${ }^{1}$, Carla Cachoni Pizzolante ${ }^{2}$, Érika Salgado Politi Braga \\ Saldanha², José Evandro de Moraes², Christine Laganá², Luciene Aparecida \\ Madeira $^{3}$, Juliana Célia Denadai ${ }^{3}$
}

${ }^{1}$ Médico veterinário - Granja Kakimoto.

${ }^{2}$ Pesquisadores científicos da Unidade de Pesquisa e Desenvolvimento de Brotas/APTA Regional/DDDAPTA/SAA-SP, Brotas-SP. Caixa Postal 9, CEP. 17380-000. ccp@apta.sp.gov.br.

${ }^{3}$ Alunas de Pós-doutorado/FMVZ-UNESP - Botucatu.

\section{Resumo}

Objetivou-se com o trabalho verificar se o uso de acidulantes na água de 600 codornas japonesas em fase final de produção, alojadas sob diferentes densidades, afetam o desempenho e qualidade de ovos. Utilizou-se um delineamento inteiramente ao acaso, com quatro tratamentos em arranjo fatorial 2×2, sendo duas densidades de 24 e 36 aves por gaiola (correspondendo a 141,67 e $94,44 \mathrm{~cm}^{2} /$ ave, respectivamente) e duas dietas hídricas (com ou sem acidulantes) e cinco repetições cada. Avaliou-se o desempenho através do consumo de ração, peso dos ovos, percentagem de postura, massa de ovos, conversão alimentar por dúzia e por quilograma e 
mortalidade. A qualidade dos ovos foi avaliada através da gravidade específica, percentagens de gema, albúmen e casca. Não foram observadas diferenças significativas para nenhuma das variáveis estudadas $(P<0,05)$ com o uso de acidulantes, mas houve efeitos significativos da densidade para a medida consumo de ração diária $(P<0,01)$, observando-se menores consumos quando da utilização da densidade $94,44 \mathrm{~cm}^{2}$. Nenhum dos tratamentos influenciou $(P>0,05)$ a qualidade externa e interna dos ovos de codornas japonesas. Concluí-se que o menor consumo de ração das aves alojadas nas maiores densidades não trouxe prejuízos à ingestão de nutrientes importantes para a manutenção da qualidade dos ovos.

Palavras-chave: aditivos, desempenho, ovos, produção, taxa de lotação na gaiola

\title{
Acidulating in water of Japanese quail (Coturnix japonica) housed under different densities
}

\begin{abstract}
The present study aimed at evaluating the effect of the acidulating water inclusion of 600 Japanese quails in the final stages of production housed under different densities affect performance and egg quality. A completely randomized experimental design was applied with four treatments in a $2 \times 2$ factorial arrangement, being two densities of 24 and 36 birds per cage (corresponding to 141.67 and $94.44 \mathrm{~cm} 2 /$ bird, respectively) and two water diets (with or without acidulating) and five replicates each. The following performance, feed intake, egg weight, egg production, egg mass, feed conversion ratio (FCR $\mathrm{kg} / \mathrm{dz}$ and $\mathrm{FCR} \mathrm{kg} / \mathrm{kg}$ ) and mortality. The quality of eggs was evaluated by specific gravity, percentages of the yolk, albumen and bark. No significant differences were observed for any of the variables studied $(P<0.05)$ using acidulating, but there were significant effects of density to measure daily feed intake $(P<0.01)$, with lower consumption when using density $94.44 \mathrm{~cm} 2$. None of the treatments influenced $(P<0.05)$ external and
\end{abstract}


internal egg quality of Japanese quail. I have concluded that the lower feed intake of birds housed in higher densities has brought losses to intake of important nutrients for the maintenance of the quality of eggs.

Keywords: additives, performance, eggs, production, stocking rate in the cage

\section{INTRODUÇÃO}

A produção de codornas desperta o interesse na comunidade científica por tratar-se de uma espécie alternativa que poderá suprir um novo nicho de mercado devido a seu rápido crescimento, maturidade precoce, alta taxa de postura e baixo consumo de ração, além do aumento da aceitação de seus produtos pelo consumidor. A mudança nos hábitos alimentares da população mundial está motivando novos esforços por parte de pesquisadores na busca por alternativas para redução dos custos de produção e aumento da produtividade através da genética, nutrição, manejo e a demanda por alimentos que atendam as questões sociais, de meio ambiente e segurança alimentar.

Devido às pressões para reduzir os custos de produção, tem-se observado um crescente interesse em elevar a densidade populacional na indústria avícola, como uma alternativa para aumentar o rendimento produtivo do plantel, embora estudos demonstrem ser um fator de manejo estressante de relevante proporção, alterando a produção e a lucratividade do lote que pode resultar em ambiente desfavorável ao bem-estar das aves, com alterações no desempenho dos lotes (LEANDRO et al, 2005). Segundo esses autores, em ampla revisão sobre o assunto, codornas, assim como perus e galinhas, estão predispostas às reações de agressividade, como a bicagem e o canibalismo, sendo que tais comportamentos se tornam mais evidentes quando as aves são alojadas em alta densidade populacional. Entretanto, a redução da área de gaiola por ave, assim como da área de comedouro e bebedouro pode causar problemas de estresse provocados pela constante competição por espaço e 
KAKIMOTO, S.K. et al. Acidulantes na água de codornas japonesas (Coturnix japonica) alojadas sob diferentes densidades. PUBVET, Londrina, V. 5, N. 37, Ed. 184, Art. 1241, 2011.

alimento, influindo no consumo de ração e, conseqüentemente, no crescimento e no desempenho produtivo dessas aves.

Pesquisas verificando o efeito das densidades populacionais de aves em gaiolas observaram melhora no desempenho, produção de ovos e mortalidade com o aumento do espaço por ave (ERNST e COLEMAN, 1996; NAGARAJAN et al., 1991; GARCIA et al., 1998; MURAKAMI et al., 2000). Em contra partida altas densidades em gaiola com a redução de área/ave pioram a postura e retardam a maturidade (HOMOSANY, 1994).

O crescimento, o desenvolvimento do aparelho reprodutivo e a eficiência produtiva das codornas são diretamente influenciados pela densidade usada nas diferentes fases de criação, recomendando-se para a obtenção de um ótimo desempenho, que durante a fase de postura as aves devam ser alojadas em gaiolas com espaço de até 107,64 cm2/ave (OLIVEIRA, 2002). Entretanto, Lopes et al. (2006) não observaram efeitos significativos nas densidades de alojamento de 94,$9 ; 108,4 ; 126,5$ e 151,8 cm2/ave e nem da interação entre as densidades e níveis de energia utilizadas (2.750, 2.900 e $3.050 \mathrm{kcal} \mathrm{EM} / \mathrm{kg}$ ), concluindo que codornas japonesas na fase de postura podem ser alojadas em gaiolas com densidade de $94,89 \mathrm{~cm} 2 /$ ave, recebendo rações contendo 2.750 $\mathrm{kcal} \mathrm{EM} / \mathrm{kg}$, sem efeitos adversos à produção.

Segundo McWard e Taylor (2000), altas densidades combinadas a fatores como $\mathrm{pH}$, temperatura, deficiência na ventilação e umidade podem criar condições ambientais favoráveis para certas bactérias benignas que utilizam o ácido úrico do esterco através de seus complexos enzimáticos e produzir amônia, causadores de estresse às aves e que podem causar prejuízos ao desempenho. Kira et al. (1996), observaram que níveis elevados de amônia no galpão, são estressantes às aves e podem causar prejuízos ao desempenho, a produção de ovos e perdas econômicas significativas ao produtor. Níveis de amônia entre 40 e 70 ppm podem reduzir o desempenho, sendo recomendado o nível de 25 ppm.

Um dos fatores que contribuíram para a obtenção da alta produtividade apresentada pela indústria avícola foi sem duvida a utilização de aditivos nas 
KAKIMOTO, S.K. et al. Acidulantes na água de codornas japonesas (Coturnix japonica) alojadas sob diferentes densidades. PUBVET, Londrina, V. 5, N. 37, Ed. 184, Art. 1241, 2011.

dietas, que quando adicionadas as rações, são capazes de melhorar o desempenho animal, as características físicas dos alimentos e até mesmo possibilitar maior utilização de ingredientes alternativos. Certamente a capacidade dos nutricionistas de utilizarem a enorme variedade de aditivos como probióticos, prebióticos, simbióticos, ácidos orgânicos, extratos vegetais e enzimas exógenas, vêm sendo, bastante enfatizado na alimentação animal (MILTENBURG, 1999; ARAúJo et al, 2007).

Usa-se o termo acidificantes ou acidulantes para designar de forma genérica de produtos compostos por ácidos orgânicos associados ou não a ácidos inorgânicos (FLEMMING, 2010), que podem otimizar tanto as condições ambientais do galpão como auxiliar nos processos de digestão e absorção dos nutrientes das rações, contribuindo no desenvolvimento de microrganismos benéficos no trato gastrintestinal, permitindo uma adequação do estado imunológico e promovendo a saúde do animal, evitando assim, a ocorrência de resíduos de medicamentos em carcaças, além de prevenir o aparecimento de microrganismos resistentes (FERKET, 2004). Além do controle específico sobre a salmonela, a manutenção de um pH gastrintestinal mais baixo decorrente da adição dos ácidos orgânicos, possibilita ainda um controle maior sobre os microrganismos que se desenvolvem no interior do estômago animal (agem diretamente como bactericidas no englúvio das aves, Adams, 1999). Isto não ocorre apenas com a salmonela, mas também com E. coli e demais agentes patogênicos. Ainda, na adição de agentes acidificantes, ocorre a quelação de minerais fazendo com que a absorção destes seja facilitada com melhor aproveitamento para os animais. O mecanismo de contato com o agente altera a membrana celular inibindo a respiração oxidativa da célula. Esta ação somada a acidificação ocorrida no meio permite o controle sobre a população bacteriana patógena havendo assim uma seleção da flora gastrintestinal (DIBNER e BUTTIN, 2002).

O uso de ácidos orgânicos, simbióticos, probióticos e prebióticos, extratos vegetais e enzimas exógenas, em substituição aos antibióticos nas dietas de aves é frequentemente discutido por nutricionistas e patologistas, com 
resultados aceitos por uns (GAMA et al, 2000.; BELLAVER et al, 2003; VAN IMMERSEEL et al., 2004 citados por VIOLA et al, 2008; VIOLA e VIEIRA, 2007; BONATO et al, 2008; VIOLA et al, 2008, SILVA et al, 2010), e contestados por outros (LIMA et al., 2003; SALAZAR et al., 2008; GRAVENA et al, 2009, MARQUES et al, 2010). De uma maneira geral, o emprego destes aditivos tem crescido no mundo inteiro, estabelecendo uma situação em que os técnicos devem estar preparados para avaliar os benefícios inerentes do emprego destas substâncias (PENZ JúNIOR, 1991).

As inúmeras possibilidades de combinações com ácidos representam achados importantes na literatura quanto aos seus efeitos melhoradores de desempenho e promotores da saúde do trato gastrintestinal das aves, principalmente sob condições de estresse. Assim, os acidulantes surgem como alternativa na melhoria nos índices de desempenho e a possibilidade da utilização de produtos menos agressivos a saúde das aves, e ao meio ambiente.

Há necessidade de obtenção e divulgação de informações adequadas sobre a correta densidade de aves em gaiolas em condições ambientais favoráveis para que maiores índices de produtividade e economia sejam alcançados na produção de ovos tornando a atividade viável e lucrativa. Em função do exposto objetivou-se com o presente estudo avaliar a suplementação de acidulantes na água de codornas japonesas (Coturnix japonica) em fase final de produção, alojadas sob diferentes densidades e verificar os possíveis efeitos sobre o desempenho e qualidade de ovos.

\section{MATERIAL E MÉTODOS}

O experimento foi realizado nas instalações da Unidade de Pesquisa e Desenvolvimento de Brotas da APTA. 600 codornas japonesas com 32 semanas de idade ao início do experimento e em fase de postura foram escolhidas ao acaso, distribuídas e alojadas em um galpão de produção de alvenaria medindo $3,0 \mathrm{~m}$ de largura e $12,0 \mathrm{~m}$ de comprimento, sendo as laterais formadas por 
0,50 $\mathrm{m}$ de muretas e 1,50 $\mathrm{m}$ de telas de arame galvanizado, com oitões fechados, cortinas laterais e cobertura de telha francesa, com gaiolas metálicas específicas para produção de ovos dispostas em duas fileiras duplas e sobrepostas, separadas por corredor central.

Utilizou-se 20 gaiolas, com dimensões de $100 \mathrm{~cm}$ de comprimento, $34 \mathrm{~cm}$ de profundidade e $16 \mathrm{~cm}$ de altura, contendo quatro divisórias internas de 25 $\mathrm{cm}$ cada, permitindo a acomodação de 24 codornas/gaiola $\left(141,67 \mathrm{~cm}^{2} /\right.$ ave $)$ e 36 codornas/gaiola (94,44 $\mathrm{cm}^{2} /$ ave), conforme o delineamento experimental e tratamentos propostos. Cada gaiola estava equipado com dois bebedouros tipo nipple e comedouros tipo calha localizado frontalmente à gaiola.

A administração da água foi feita através de duas caixas de água com capacidade de 34 litros cada. Em uma delas foi adaptada uma bomba dosadora aferida para diluir $0,5 \mathrm{ml}$ de acidulante para cada litro, que atendeu duas linhas de gaiola, sendo uma de cala lado do galpão. A outra caixa forneceu água sem acidulante para as outras duas linhas de gaiolas.

O período experimental de 112 dias foi dividido em quatro ciclos de 28 dias cada. A temperatura no interior do galpão, durante o período do experimento, foi aferida com auxílio de um termômetro de mínima e máxima.

Utilizou-se um delineamento inteiramente ao acaso, com quatro tratamentos em arranjo fatorial $2 \times 2$, sendo duas densidades de 24 e 36 aves por gaiola (correspondendo a 141,67 e 94,44 $\mathrm{cm}^{2} /$ ave, respectivamente) e duas dietas hídricas (com ou sem acidulantes) e cinco repetições (Tabela 1).

A ração de produção utilizada foi formulada à base de milho e farelo de soja e as matérias-primas tabeladas por Rostagno et al. (2005) e está apresentada na Tabela 2. 
Tabela 1. Tratamentos experimentais.

\begin{tabular}{|c|c|c|}
\hline Trat. & Densidades & Acidulante na água \\
\hline 1 & 24 codornas/gaiola ou $141,67 \mathrm{~cm}^{2} /$ ave & Sem inclusão \\
\hline 2 & 36 codornas/gaiola ou $94,44 \mathrm{~cm}^{2} /$ ave & Sem inclusão \\
\hline 3 & 24 codornas/gaiola ou $141,67 \mathrm{~cm}^{2} /$ ave & $\begin{array}{c}\text { Com inclusão (ácidos acético, } \\
\text { lático e fosfórico) }\end{array}$ \\
\hline 4 & 36 codornas/gaiola ou $94,44 \mathrm{~cm}^{2} /$ ave & $\begin{array}{c}\text { Com inclusão (ácidos acético, } \\
\text { lático e fosfórico) }\end{array}$ \\
\hline
\end{tabular}

Tabela 2. Composição percentual dos ingredientes e níveis nutricionais calculados para a ração experimental.

\begin{tabular}{lc}
\hline Ingredientes (\%) & Ração experimental (kg) \\
\hline Milho moído & 52,45 \\
Farelo de soja & 36,10 \\
Óleo de soja & 1,45 \\
Calcário calcítico & 6,98 \\
Fosfato bicálcico & 1,94 \\
Sal comum & 0,35 \\
Suplemento vitamínico e mineral ${ }^{1}$ & 0,60 \\
\hline Total & 100,00 \\
\hline Níveis Nutricionais Calculados & 2750 \\
\hline Energia metabolizável (kcal/kg) & 21 \\
Proteína bruta (\%) & 3,27 \\
Fibra bruta (\%) & 3,20 \\
Cálcio (\%) & 0,46 \\
Fósforo disponível (\%) & 0,45 \\
Metionina (\%) & 0,80 \\
Metionina + Cistina (\%) & 1,16 \\
Lisina (\%) & \\
\hline${ }^{1}$ Composição dos Suplementos Vitamínico e Mineral Multimix®/kg de produto. Ácido fólico \\
80,000 mg; Ácido Pantotênico 5.000,000 mg; Colina 43.400,000; Metionina 181.150,000; \\
Niacina 6.680,000 mg; Se 33,330 mg; Vit. A 1.660.000,000 UI; Vit. B1 500,00 mg; Vit. B12 \\
1.680,000 mcg; Vit B2 1.000,000 mg; Vit. B6 666,700 mg; Vit. D3 208.400,000 UI; Vit. E \\
3.360,000 mg; Vit. K3 500,000 mg; Cu 1.333,000 mg; Fe.8.333,300 mg; I. 200,000 mg; \\
Mn.11.666,600 mg; Zn. 8.333,300 mg.
\end{tabular}


Para pesagem das aves e da ração utilizou-se uma balança eletrônica de precisão, com capacidade de $6 \mathrm{~kg}$ e, para pesagem dos ovos, uma balança eletrônica com capacidade de $500 \mathrm{~g}$ e precisão 0,01g. As rações experimentais foram acondicionadas em baldes plásticos específicos para cada parcela experimental. Os ovos foram contados e coletados todos os dias e o consumo das dietas foram avaliados, semanalmente, através da diferença da quantidade de ração fornecida e a sobra nos comedouros.

Durante o período experimental, tanto as rações experimentais, colocadas duas vezes ao dia, como a água, foram fornecidos à vontade. 0 programa de iluminação foi de $17 \mathrm{~h}$ diárias e as aves foram vacinadas contra a doença de Newcastle e bronquite infecciosa via aspersão a cada 60 dias. A mortalidade foi registrada no dia do evento.

Ao final do experimento avaliou-se o peso dos ovos (PO), a percentagem de postura (\%Post), a massa de ovos (MO), o consumo de ração (CR), a conversão alimentar (CA) por dúzia e por quilograma de ovos produzidos e a mortalidade (\% Mort.). A qualidade dos ovos foi verificada ao final de cada período de 28 dias, retirando-se dois ovos de cada parcela, durante três dias consecutivos, avaliando-se gravidade específica (GE), percentagens de albúmen, gema e casca, Unidades Haugh (UH) e índice gema (IG). Os resultados foram submetidos à análise estatística através da ANOVA e o contraste entre médias de tratamentos, quando significativos, ao teste de Tukey a $5 \%$, com auxílio do pacote computacional SISVAR (FERREIRA, 2000).

\section{RESULTADOS E DISCUSSÃO}

As médias de temperatura ambiente e umidade relativa do ar registrada para as máximas e mínimas no galpão experimental durante todo o período experimental foram: $20,9{ }^{\circ} \mathrm{C}$ e $53 \%$ e $29,0{ }^{\circ} \mathrm{C}$ e $84 \%$, respectivamente. Os resultados médios de desempenho estão apresentados na Tabela 3. 
Tabela 3. Desempenho produtivo de codornas japonesas, alojadas sob diferentes densidades e recebendo acidulantes na água.

\begin{tabular}{|c|c|c|c|c|c|c|c|}
\hline Variáveis & $\begin{array}{c}\text { Peso } \\
\text { ovo (g) }\end{array}$ & $\begin{array}{c}\text { Postura } \\
(\%)\end{array}$ & $\begin{array}{c}\text { Massa de } \\
\text { ovo } \\
\text { (g/ave/dia) }\end{array}$ & $\begin{array}{l}\text { Consumo } \\
\text { (g/ave/dia) }\end{array}$ & $\begin{array}{c}\mathrm{CA} / \mathrm{dz} \\
(\mathrm{kg} / \mathrm{dz})\end{array}$ & $\begin{array}{c}\mathrm{CA} / \mathrm{kg} \\
(\mathrm{kg} / \mathrm{kg})\end{array}$ & $\begin{array}{c}\text { Mort. } \\
(\%)\end{array}$ \\
\hline
\end{tabular}

\begin{tabular}{|c|c|c|c|c|c|c|c|}
\hline \multicolumn{8}{|l|}{$\begin{array}{l}\text { Densidade } \\
\text { ( } \mathrm{cm}^{2} / \text { ave) }\end{array}$} \\
\hline \multirow[t]{2}{*}{$24(141,67)$} & 11,2 & 88 & 10,12 & $31,67 b$ & 0,423 & 3,152 & 0,34 \\
\hline & 6 & & & & & & \\
\hline \multirow[t]{2}{*}{$36(94,44)$} & 11,2 & 90 & 9,95 & $30,06 a$ & 0,408 & 3,034 & 0,47 \\
\hline & 1 & & & & & & \\
\hline \multicolumn{8}{|l|}{ Acidulante } \\
\hline Com & 11,21 & 89 & 10,02 & 30,81 & 0,416 & 3,091 & 0,37 \\
\hline Sem & 11,26 & 89 & 10,04 & 30,92 & 0,417 & 3,095 & 0,44 \\
\hline Média geral & 11,24 & 89 & 10,03 & 30,86 & 0,417 & 3,093 & 0,40 \\
\hline CV (\%) & 1,6 & 3,94 & 3,91 & 4,46 & 5,50 & 5,26 & 14,5 \\
\hline
\end{tabular}

Na coluna, médias seguidas por letras iguais não diferem entre si $(P>0,05)$ pelo teste de Tukey.

Não foram observadas diferenças significativas $(P>0,05)$ para peso dos ovos, percentagem de postura, massa de ovo, conversão alimentar por dúzia, conversão alimentar por quilo e mortalidade estudadas. Houve efeito isolado da densidade de aves para a característica consumo de ração diário. Observouse que o menor consumo de ração foi obtido na densidade $94,44 \mathrm{~cm}^{2}$. Não foram constatadas interações significativas entre densidade e acidulantes $(P>0,05)$.

Resultados semelhantes foram observados por Rocha et al (2010), trabalhando com prebióticos, ácidos orgânicos e probióticos em rações para frangos de corte. Segundo esses autores os aditivos não influenciaram os parâmetros peso vivo, ganho de peso, consumo de ração e conversão 
KAKIMOTO, S.K. et al. Acidulantes na água de codornas japonesas (Coturnix japonica) alojadas sob diferentes densidades. PUBVET, Londrina, V. 5, N. 37, Ed. 184, Art. 1241, 2011.

alimentar. Mesmo o aumento da quantidade de mananoligossacarídeos ou a associação desses com ácidos orgânicos não foi suficiente para melhorar o desempenho das aves.

Em trabalho semelhante, VIOLA e VIEIRA (2007), suplementaram ácidos orgânicos e inorgânicos em dietas para frangos de corte, e não verificaram efeito do uso desses sobre o ganho de peso e o consumo de ração, mas obtiveram benefícios sobre a conversão alimentar. Esses autores atribuíram os resultados obtidos em relação à conversão alimentar a uma possível redução nos desafios microbiológicos por ação dos acidificantes, a benefícios em nível de nutrição celular intestinal ou à ativação enzimática em nível intestinal.

Já Gama et al (2000) utilizando ácidos orgânicos em rações de poedeiras comerciais observaram efeitos positivos sobre a produção de ovos e peso das aves. Ainda, Cave et al. (1984) suplementando acidificantes nas dietas de frangos de corte observou redução da ingestão de alimentos e do ganho de peso, sugerindo que ácidos comprometem a palatabilidade da dieta, reduzindo o consumo pelas aves.

Os acidulantes são substâncias que têm como resposta primária a redução do pH. Entretanto, pH reduzido, por si só, pode não gerar alteração de desempenho, visto que a ação antimicrobiana é mais pronunciada na presença dos ácidos fórmico, acético e láctico (possuem rotas metabólicas distintas), especialmente após absorção intestinal (VIOLA et al, 2008).

$O$ efeito da densidade sob o desempenho produtivo de codornas tem sido objeto de estudo de vários autores e as respostas têm sido divergentes. Em muitos trabalhos observa-se melhora significativa do desempenho com a diminuição da densidade.

Garcia et al. (1998) observaram melhor desempenho econômico/ave/dia com a utilização de $173,7 \mathrm{~cm}^{2} /$ ave. Murakami et al. (2000) verificaram melhor desempenho com a taxa de lotação de $152 \mathrm{~cm}^{2} /$ ave. Leandro et al. (2005), testando 3 tipos de debicagem (nenhuma, leve e severa) e duas densidades ( $75 \mathrm{~cm}^{2}$ /ave e $103 \mathrm{~cm}^{2} /$ ave) concluíram que a densidade de $75 \mathrm{~cm}^{2} /$ ave pode ser utilizada na fase de postura, sem perdas na produtividade. Lopes et al. 
KAKIMOTO, S.K. et al. Acidulantes na água de codornas japonesas (Coturnix japonica) alojadas sob diferentes densidades. PUBVET, Londrina, V. 5, N. 37, Ed. 184, Art. 1241, 2011.

(2006) não observaram efeitos significativos nas densidades de alojamento utilizadas: 94,$89 ; 108,4 ; 126,5$ e $151,8 \mathrm{~cm}^{2}$ /ave e nem da interação entre as densidades e níveis de energia utilizadas $(2.750,2.900$ e $3.050 \mathrm{kcal} \mathrm{EM} / \mathrm{kg})$, concluindo que codornas japonesas na fase de postura podem ser alojadas em gaiolas com densidade de $94,89 \mathrm{~cm}^{2} /$ ave, recebendo rações contendo 2.750 $\mathrm{kcal} \mathrm{EM/kg}$, sem efeitos adversos à produção das aves.

Os resultados de qualidade de ovos obtidos estão apresentados na Tabela 4.

Tabela 4. Qualidade de ovos de codornas japonesas, alojadas sob diferentes densidades e recebendo acidulantes na água.

\begin{tabular}{|c|c|c|c|c|c|c|c|}
\hline Variáveis & $\begin{array}{c}\text { Peso } \\
\text { ovo (g) }\end{array}$ & $\begin{array}{l}\text { Gravidade } \\
\text { específica }\end{array}$ & $\begin{array}{c}\text { Gema } \\
\%\end{array}$ & $\begin{array}{c}\text { Albúmen } \\
\%\end{array}$ & $\begin{array}{c}\text { Casca } \\
\%\end{array}$ & $\mathrm{UH}$ & IG \\
\hline $\begin{array}{l}\text { Densidade } \\
\text { ( } \mathrm{cm}^{2} / \text { ave) }\end{array}$ & & & & & & & \\
\hline $24(141,67)$ & 11,60 & 1,074 & 31,13 & 60,94 & 8,05 & $\begin{array}{c}86,9 \\
8\end{array}$ & $\begin{array}{c}0,4 \\
4\end{array}$ \\
\hline $36(94,44)$ & 11,50 & 1,075 & 31,09 & 60,75 & 8,04 & $\begin{array}{c}85,6 \\
0\end{array}$ & $\begin{array}{c}0,4 \\
4\end{array}$ \\
\hline Acidulante & & & & & & & \\
\hline Com & 11,58 & 1,075 & 31,05 & 60,68 & 8,04 & $\begin{array}{c}86,6 \\
0\end{array}$ & $\begin{array}{c}0,4 \\
4\end{array}$ \\
\hline Sem & 11,52 & 1,075 & 31,18 & 61,00 & 8,05 & $\begin{array}{c}85,9 \\
9\end{array}$ & $\begin{array}{c}0,4 \\
4\end{array}$ \\
\hline Média & 11,55 & 1,075 & 31,11 & 60,84 & 8,05 & $\begin{array}{c}86,3 \\
0\end{array}$ & $\begin{array}{c}0,4 \\
4\end{array}$ \\
\hline CV (\%) & 5,98 & 0,48 & 5,51 & 3,64 & 4,87 & 5,38 & $\begin{array}{c}6,4 \\
5\end{array}$ \\
\hline
\end{tabular}


Não foram observadas diferenças significativas $(P>0,05)$ para nenhuma das variáveis estudadas. Os tratamentos não influenciaram a qualidade externa e interna dos ovos de codornas japonesas, apesar do menor consumo de ração obtido nas maiores densidades, indicando que não houve prejuízos à ingestão de nutrientes importantes para a manutenção da qualidade dos ovos.

Resultados semelhantes foram encontrados por Bonato et al (2008) com fornecimento isolado ou associado de acidificantes e extratos vegetais e não observaram alteração da qualidade dos ovos de poedeiras comerciais em final de ciclo de produção e Gama et al, (2000) com a utilização de ácidos orgânicos para poedeiras comerciais não observaram interferência na qualidade interna e peso dos ovos.

Segundo Garcia (1991) e Brake (1995), citados por Gama et al, (2000), a qualidade interna de ovos, medida por unidades Haugh, está ligada à nutrição, linhagem e idade da ave, bem como à temperatura de armazenagem dos ovos, dessa forma, tendo pouca correlação com a presença de acidificantes na dieta.

Dados referentes à utilização de acidulante e extratos vegetais são poucas, entretanto alguns autores que trabalharam com ácidos específicos obtiveram resposta à utilização dos mesmos como é o caso de Tserbene-Gouse et al. (1992), citado por Bonato et al. (2008), que obtiveram resultados positivos com a suplementação com 25, 50, 75, 100, 125, 400 e 500 ppm de vitamina $C$ na produção de ovos de poedeiras comerciais. Os autores explicam que a melhora na produção de ovos pode ter sido decorrente de um maior aproveitamento dos nutrientes das dietas, visto que os aditivos utilizados atuaram sobre a microflora intestinal, melhorando consequentemente a saúde das aves.

\section{CONCLUSÕES}

Os resultados obtidos neste estudo permitem afirmar que, nas condições experimentais utilizadas, a adição de um mix de ácidos orgânicos e inorgânico 
KAKIMOTO, S.K. et al. Acidulantes na água de codornas japonesas (Coturnix japonica) alojadas sob diferentes densidades. PUBVET, Londrina, V. 5, N. 37, Ed. 184, Art. 1241, 2011.

na água de bebida não interferiu no desempenho e na qualidade dos ovos de codornas poedeiras em fase final de produção. A densidade de 94,44 cm²/ave pode ser utilizada sem que haja prejuízos ao desempenho produtivo.

\section{REFERÊNCIAS BIBLIOGRÁFICAS}

ADAMS, C.A. Nutricines. Food components in Health and Nutrition. Nottingham. Nottingham Univ. Press. 1999. 128P.

ARAÚJO, J.A.; SILVA, J.H.V.; AMÂNCIO, A.L.L.; LIMA, M.R.; LIMA, C.B. Uso de aditivos na alimentação de aves. Acta Veterinaria Brasílica, v.1, n.3, p.69-77, 2007.

BELLAVER, C.; JAENESKI, F.R.; COSTA, C.F.; ÁVILA, V.S. Relatório de projeto de pesquisa sobre a acidificação de dietas para frangos de corte com ácido lático. Contrato PURAC / Embrapa Suínos e Aves. Concórdia. Embrapa Suínos e Aves. 2003.

BONATO, M.A.; SAKOMURA, N.K.; PIVA, G.H.; BARBOSA, N.A.A.; MENDONÇA, M.O.; FERNANDES, J.B.K. Efeito de acidificantes e extratos vegetais sobre o desempenho e qualidade de ovos de poedeiras comercias. ARS VETERINARIA, v.24, n.3, 186-192, 2008.

CAVE, N.A.G. Effect of dietary propionic and lactic acids on feed intake by chicks. Poultry Science, v.63, p.131-134, 1984.

DIBNER, J..J.; BUTTIN, P. Use of Organic Acids as a Model to Study the Impact of Gut Microflora on Nutrition and Metabolism. Journal of Applied Poultry Research, v.11, n.4, p.453-463, 2002.

ERNST, R.A., COLEMAN, T.M. The influence of floor space on growth, egg production, fertility and hatchability of Coturnix coturnix japonica. Poultry Science, v.45, p.437-440, 1996.

FERKET, P. R. Alternatives to antibiotics in poultry production:responses, practical experience and recommendations. Proceedings of Alltech`s Annual Symposium, Lexington, USA, p. 54-67. 2004.

FERREIRA, D,F. Sistema para análise de variância para dados balanceados (SISVAR). Lavras: UFLA; 2000; 92 p.

GAMA, N.M.S.Q.; OLIVEIRA, M.B.C.; SANTIN, E.; BERCHIERI JÚNIOR, A. Ácidos orgânicos em rações de poedeiras comerciais. Ciência Rural, v. 30, n. 3, p. 499-502, 2000.

GARCIA, E.A.; MENDES, A.A.; GONZALES, E; SILVA, A.B.P.; SALDANHA, E.S.P.B. Desempenho produtivo e econômico de codornas poedeiras alojadas sob diferentes taxas de lotação da gaiola. Boletim da Indústria Animal, v. 55. n. 2, p. 185-188, 1998.

GRAVENA, R.A.; MARQUES, R.H.; SILVA, J.D.T.; HADA, F.H.; SILVA, V.K.; MUNARI, D.P.; MORAES, V.M.B. Uso da Valeriana officinalis em dietas de codornas japonesas na fase de postura. Biotemas, v. 22, n. 4, p. 185-191, 2009.

LEANDRO, N.S.M.; VIEIRA, N.S.; MATOS, M.S.; CAFÉ, M.B.; STRINGHINI, J.H.; SANTOS, D.A. Desempenho produtivo de codornas japonesas (Coturnix Coturnix Japonica) submetidas a diferentes densidades e tipos de debicagem. Acta Scientiarum. Animal Sciences. v. 27, n. 1, p. 129-135, 2005.

LIMA, A.C.F.; PIZAURO JÚNIOR, J.M.; MACARI, M.; MALHEIROS, E.B. Efeito do uso de probiótico sobre o desempenho e atividade de enzimas digestivas de frangos de corte. Revista Brasileira de Zootecnia, v.32, n.1, p.200-207, 2003. 
LOPES, I.R.V.; FUENTES, M.F.F.; FREITAS, E.R.; SOARES, M.B.; RIBEIRO, O.S. Efeito da densidade de alojamento e do nível de energia metabolizável da ração sobre o desempenho zootécnico e características dos ovos de codornas japonesas. Revista Ciência Agronômica, v.37, n.3, p.369-375, 2006.

MARQUES, R.H.; GRAVENA, R.A.; SILVA, J.D.T.; HADA, F.H.; SILVA, V.K.; MALHEIROS, R.D.; MORAES, V.M.B. Inclusão da camomila no desempenho, comportamento e estresse em codornas durante a fase de recria. Ciência Rural, Santa Maria, v.40, n.2, p.415-420, fev, 2010

MILTENBURG, G. Tendência futura do uso de aditivos na nutricao de aves. In: IV Seminário Internacional en Ciencias Avicolas, AMEVEA. Santa Cruz, Bolivia, 24 al 27 de Junio de 1999. p. 81-84.

N.R.C. - NATIONAL RESEARCH COUNCIL. Nutrient Requeriments of Poultry. $9^{\text {th }}$ ed. Washington: National Academy of Sciences, 1994, 156p.

NAGARAJAN, S.; NARAHARI, D.; JAYAPRASAD, I.A.; THYAGARAJAN, D. Influence of stocking density and layer age on production traits and egg quality in japanese quail. British Poultry Science, v.32, p.243-8, 1991.

OLIVEIRA, B.L. Manejo racional e produtividade das codornas (Coturnix coturnix japonica). In: SIMPÓSIO INTERNACIONAL DE COTURNICULTURA, 1., 2002, Lavras: UFLA, 2002. p.77-84.

PENZ JÚNIOR, A.M. Hipótesis que justifican el uso de acidos organicos en las dietas para aves e cerdos. Avicultura Professional, v.9, p.46, 1991.

ROCHA, A.P. da.; ABREU, R.D.; COSTA, M.C.M.M. da.; OLIVEIRA, G.J.C. de.; ALBINATI, R.C.B.; PAZ, A.S. da.; QUEIROZ, L.G. de.; PEDREIRA, T.M. Prebióticos, ácidos orgânicos e probióticos em rações para frangos de corte. Revista Brasileira de Saúde e Produção Animal, v.11, n.3, p.793-801 jul/set, 2010

ROSTAGNO, H.S.; ALBINO, L.F.T.; DONZELE, J.L.; GOMES, P.C.; OLIVEIRA, R.F.; LOPES, D.C.; FERREIRA, A.S.; BARR, S.L.T. Tabelas brasileiras para aves e suínos: composição de alimentos e exigências nutricionais. $2^{a}$. ed. Viçosa, MG: Universidade Federal de Viçosa, 2005. 186p.

SALAZAR, P.C.R.; ALBUQUERQUE, R.; TAKEARA, P.; TRINDADE NETO, M.A.; ARAÚJO, L.F. Efeito dos ácidos lático e butírico, isolados e associados, sobre o desempenho e morfometria intestinal em frangos de corte. Brazilian Journal Veterinary Research and Animal Science, v. 45, n. 6, p. 463-471, 2008.

SILVA, J.D.T.; GRAVENA, R.A.; MARQUES, R.H.; SILVA, V.K.; HADA, F.H.; MORAES, V.M.B.; MALHEIROS, R.D. Passionflower supplementation in diets of Japanese qualis at rearing and laying periods. Revista Brasileira de Zootecnia, v.39, n.7, p.1530-1537, 2010

VIOLA, E.S; VIEIRA, S.L.; TORRES, C.A.; FREITAS, D.M.; BERRES, J. Desempenho de frangos de corte sob suplementação com ácidos lático, fórmico, acético e fosfórico no alimento ou na água. Revista Brasileira de Zootecnia, v.37, n.2, p.296-302, 2008

VIOLA, E.S.; VIEIRA, S.L. Suplementação de acidulantes orgânicos e inorgânicos em dietas para frangos de corte: desempenho zootécnico e morfologia intestinal. Revista Brasileira de Zootecnia, v.36, n.4, p.1097-1104, 2007 (supl.). 